\title{
Impact of ‘Pay for Performance’ on Utilization of Health Services and Quality of Care in Low and Middle Income Countries
}

Mubashir Zafar*

Dow University of Health Sciences, School of Public Health, Pakistan

\begin{abstract}
The "pay-for-performance" (P4P) tool has been used in low and middle income countries in order to improve the performance of health care providers. It helps to improve the quality of health care and efficiency but it has some drawback like its only focus on a single condition and do not reflect the complexity of caring for patients who had multiple conditions. Objective of this paper is to determine the P4P impact of health care services. Different documents, papers, reports and literature were searched from 2010 to 2012 were included. Medline, Embase, and Google search engine were used for this purpose. "Pay for performance" increase the utilization of health services and quality of health services but its constrained by certain challenges such as immature NGO service sector with weak managerial and technical capacity, conditional cash transfers to households in countries with a large proportion of the population was considered poor. Improvement of quality of health services by incentive pay to stakeholder in developing countries.
\end{abstract}

Keywords: Quality; Healthcare; Reimbursement; Pay for performance; Healthcare provider

\section{Introduction}

Health is a fundamental human right as well as a central input to poverty reduction and socioeconomic development. A greater investment in health is envisaged to save millions of lives in most developing countries and has the potential to produce enormous economic gains. Cost-effective interventions for controlling major diseases exist, but it is perceived that the existing financial and human resource gaps and limited district level managerial capacity are hampering the efforts to extend essential health services to the poor [1].

Healthcare financing is important issues that are faced by developing countries. Scarce resources, burden of diseases, population growth, unregulated private sector, budget constraints, inefficient use of available health budget, weak tax base and administration, are important factors that leads to financing of health care more were more complex [1]. These factors may well characterize by health systems of many developing countries. Healthcare financing is the most vital part of health policy planning and implementation [2].

Poor people do not utilize essential preventive, curative and life extending primary care services, even when those services are available at their door step [2]. Understanding the reasons for not unitization of health services because the policy and barriers were not addressed. Programmatic approaches which can increase effective utilization are central to the success of many current efforts to improve health in the developing world [3]. Deficiencies in the quality of care, caused by lack of knowledge, insufficient resources, organizational rigidities, and inappropriate incentives for providers, impede the ability of health systems to improve health outcomes for the poor. This paper basically looks at performance based incentive type of financing intervention that has been applied in several different ways in developing countries including Pakistan to address the problems of underutilization and low quality of health services. The focus for "pay for performance" intervention is on demand and supply side financial and material (examples: food, travel vouchers) incentives that can be used to improve utilization and quality of mobile health care services, especially for the poor. Researcher's attention focused on interventions that compare payment or use of material goods to indicators of performance or defined actions (example: TB patient given presents to take medicine) that are closely correlated with improved health outcomes.

The Government of Pakistan has been spending 0.6 to $1.19 \%$ of its GDP and 5.1 to $11.6 \%$ of its development expenditure on health over the last 10 years $[3,4]$. Pakistan principally uses two modes of health financing - taxation and out-of-pocket payments. The average monthly household out-of-pocket expenditure on health has been reported to be Rs. 358 for 2001/2002 in Pakistan. This is equal to 5.2\% of the total monthly household expenditure and total per-capita health expenditure in Pakistan is reported to be between Rs. 750 to 800 ( US $\$ 12$ to 13 ) [5,6]. Foreign aid as a percentage of total health sector allocation has ranged from $4-16 \%$ over the last several years and these global funding initiatives are helping to minimize the financial and material constraints that prevent health systems from performing well. Important point to note that even when providers have the knowledge, skills and necessary inputs (human resources, drugs, equipment, supplies) to produce a sufficient quantity of quality services to meet population needs [6], there are low utilization, substandard quality, and poor health outcomes throughout the developing world including Pakistan [7]. When consumers are aware of health benefits and know that health care services are physically and financially accessible, they do not necessarily obtain services [7]. Without system building efforts that focus on the currently inadequate (and often perverse) incentives faced by the key health system actors (providers and consumers) it is unlikely that ambitious improvements in health outcomes can be attained. This paper argues that pay-for-performance schemes that are appropriately designed to address the underlying barriers and constraints to strong health system performance, it has the potential to contribute significantly for improving the health outcomes in

*Corresponding author: Mubashir Zafar, Dow University of Health Sciences, School of Public Health, Pakistan, Tel: 00923332306287; Fax: 202-476-5898; E-mail: mubashirzafar900@gmail.com

Received December 16, 2013; Accepted January 11, 2014; Published January 13, 2014

Citation: Zafar M (2014) Impact of 'Pay for Performance' on Utilization of Health Services and Quality of Care in Low and Middle Income Countries. Health Care Current Reviews 2: 116. doi: 10.4172/2375-4273.1000116

Copyright: $\odot 2014$ Zafar M, et al. This is an open-access article distributed under the terms of the Creative Commons Attribution License, which permits unrestricted use, distribution, and reproduction in any medium, provided the original author and source are credited. 
developing countries including Pakistan.

\section{Methods}

We searched three databases: Medline, Embase, and Google, twenty-five expressions were entered in each database. Articles written in English published between January 2010 and December 2012 were eligible for inclusion. Authors independently reviewed all titles generated by the search procedure and constructed a preliminary list of articles. These articles were subjected to abstract review and full texts of potentially relevant articles were obtained. Two authors independently assessed their eligibility for inclusion. Authors independently extracted relevant data from identified reviews using the same abstraction form containing the following elements: search period, number of studies, type of studies, sector and country in which studies were conducted, and a summary of the main results for each of the domains. The findings from identified reviews are compared and expanded with findings from several recently published primary studies that are not included in any of the reviews but that do provide relevant information. These studies were not identified from an additional systematic review, but from our knowledge of the current evidence base on $\mathrm{P} 4 \mathrm{P}$ effects. Although there may be more studies than the ones we discuss, comparing our results with the findings from additional studies we are aware of provides additional insight in the effects of $\mathrm{P} 4 \mathrm{P}$ and enables us to draw stronger conclusions.

\section{"Pay-for-Performance"?}

"Transfer of money or material goods in exchange for measurable action or achieving a predetermined performance target" [2].

Demand side "Pay for performance" interventions include conditional cash transfer programs pay monthly subsidies to households conditional on defined actions such as taking children for well-care visits or keeping them in school. Supply side "Pay for Performance" includes the full range of financial and material incentives that are aimed at inspiring changes in behavior among public and non-state sector institutions, managers, and health workers that ultimately result in improved Performance [2].

Differences in health status between poor and rich can be explained by differences in the utilization of essential health services. For example, for the 56 countries included in the analysis presented in Graph 1, an average of $34 \%$ of children born to the poorest families are fully immunized in contrast to $62 \%$ of rich children. This indicates that the poor are not being reached as effectively as the rich with the range of strategies countries use to motivate families to immunize their children. Graph 2, shows inequality in utilization of services to medically treat acute respiratory infections among richest and poorest quintile $[8,9]$.

\section{Healthcare Facilities Largely Underutilized in Developing Countries including Pakistan}

In developing countries, health status of the poor is inferior to the rich, utilization of services is lower for the poor than the rich, and government subsidies are not effectively targeted to for the poor. When services were accessed by the poor, they are often of inadequate quality [10]. Globally, 80 out of 1000 infants born to the poorest socioeconomic quintile were dying, in contrast to an average infant mortality rate of 5 per 1,000 live births among the richest [11]. Wide disparities in health status and utilization of essential public health services indicate that delivery system priorities not be the same for population groups with different socioeconomic characteristics [12] (Table 1).
The qualities of care in health care facilities in developing countries are generally poor. That's why people in these countries low utilization of services from these health care facilities. There are several reasons contribute to low utilization of healthcare facilities, most important factor they operate only a few hours a day, absence of quality inputs like basic services are not available, not have electricity and no female staff, gaps in the availability of drugs, shortage of contraceptives, not have vaccines and lack de-worming medicines, geographical access, inattentive attitude of the staff and out-of-pocket payments for supposedly free services. As result of low utilization of healthcare services, physical infrastructure of healthcare centers are sometimes used for other purposes like Union Council offices and other government offices in Pakistan [12].

Public spending in Pakistan is not effectively targeted to benefit the poorest. Benefit- incidence analyses of surveys on health that have been conducted in Pakistan indicate that, on average, the richest socioeconomic quintile receives over twice as much financial benefit as the poorest quintile from government health service expenditures $[7,12]$.

Studies on inequalities in utilization and expenditures on health services indicate that richer groups are more likely than poor groups to see a medical practitioner and obtain medicines when sick. However, household expenditures as a percentage of household income are not higher for richer households than for poor ones [13]

Differences in utilization of healthcare faculties between the poor and rich that suggest policy recommendations, considered five determinants of demand: income, service quality, access, direct user charges and gender [11].

Quality of care in public healthcare facilities available to the poor is lower than that available to the rich as measured by availability of drugs, staff skills and the quality of health facilities [14]. Physical access to health care and the opportunity costs posed by having to travel to obtain care are obstacles that prevent utilization of care by the poor more than the rich. User fees for medical consultations are also more of a burden for the poor and constrain utilization unless quality improvements compensate [15].

\section{Pay-for-Performance can Contribute to Improving the Performance of Health Systems}

The causes of poor quality of essential services and where "Pay for performance" interventions may be effective are best examined within the broader context of the health system. All health systems have to carry out the same basic functions regardless of how they are organized or which health interventions they are trying to deliver. These functions are the development of human and other key resources; service provision; financing and stewardship [14].

Table 2 shows that one of distinguish feathers of "pay for performance" solutions is "contract and incentive" approach that sets into motion a dynamic that encourages the many actors in the health system to respond with innovative solutions [16]. Conditional cash transfer $(\mathrm{CCT})$ is a scheme in which provide cash against on certain condition.

\section{Evidence and Illustrative Cases}

Evidence from several schemes that cover a large portion of country population shows how elements of these schemes address underlying constraints or performance problems that inhibit the poor from utilizing essential services and for services to be of appropriate quality. 
Citation:Zafar M (2014) Impact of 'Pay for Performance' on Utilization of Health Services and Quality of Care in Low and Middle Income Countries. Health Care Current Reviews 2: 116. doi: 10.4172/2375-4273.1000116

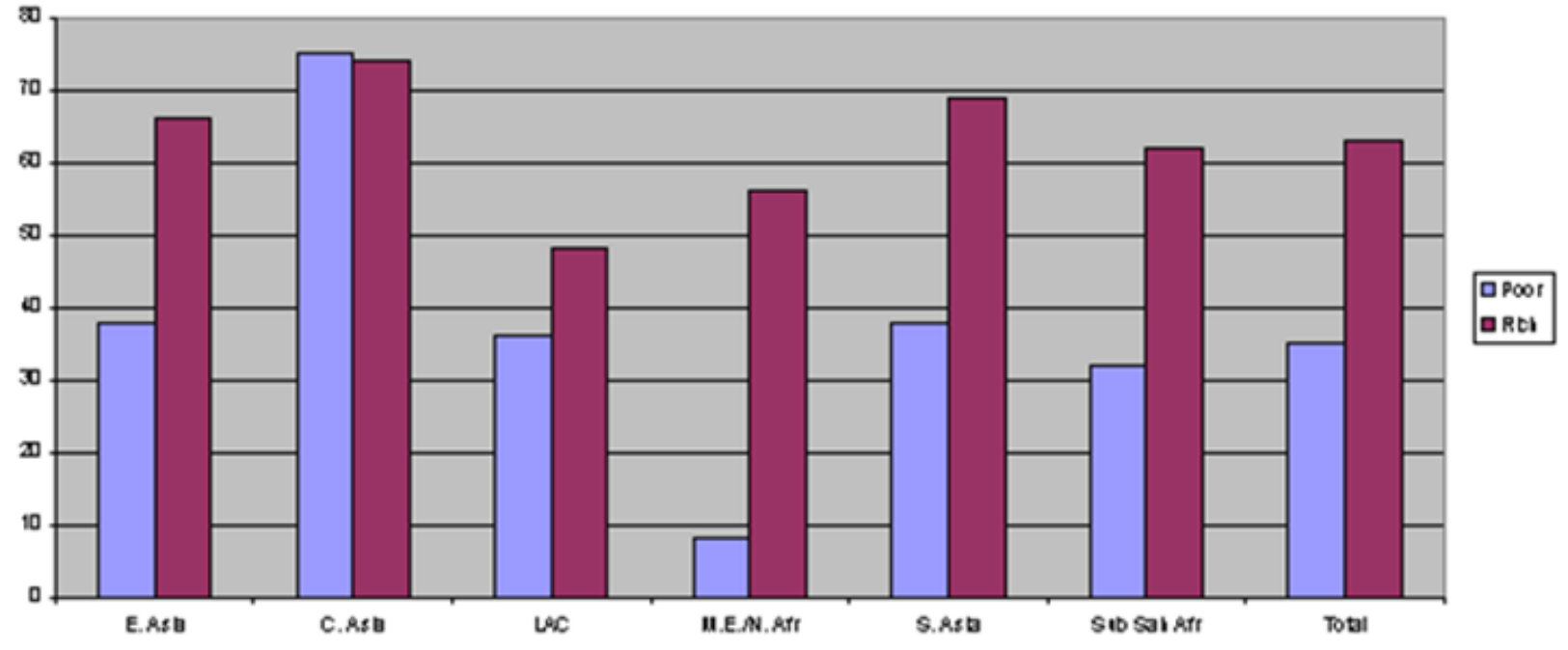

Graph 1: Inequalities in Full Immunization Coverage among poor and Rich -2005

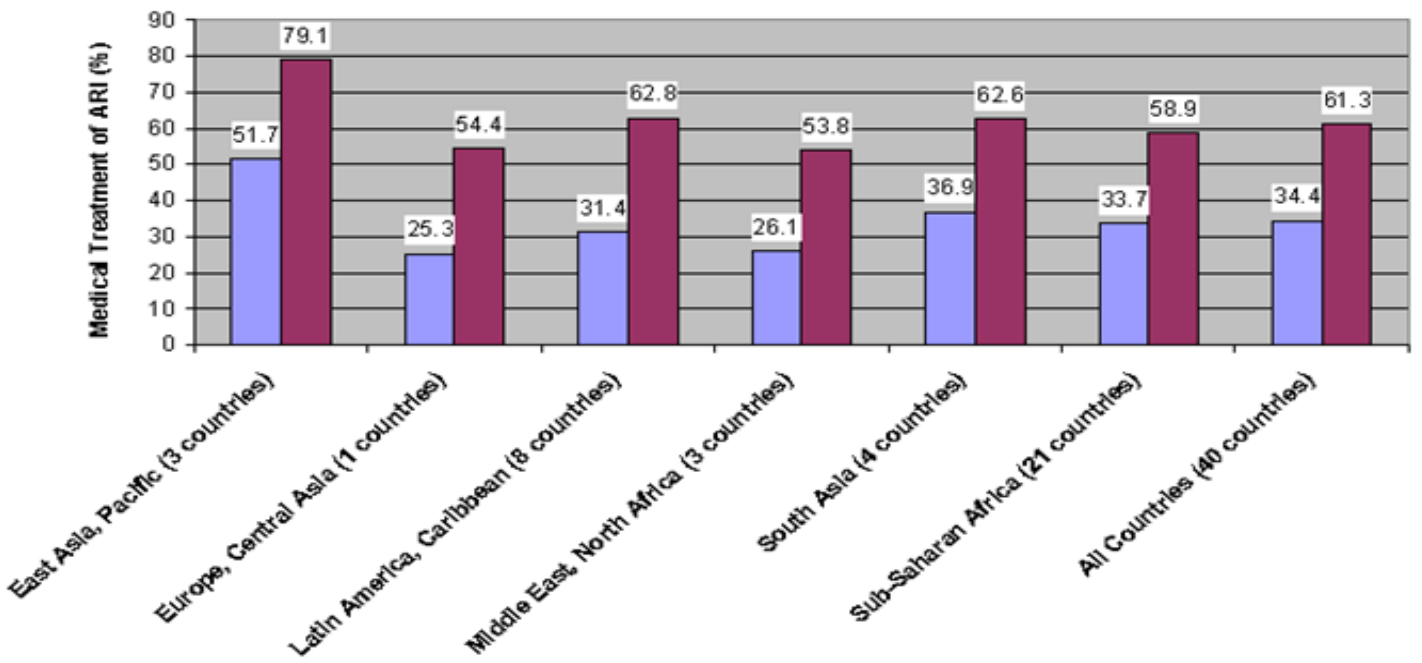

Graph 2: Medical Treatment of ARI -- Rates among Poor and Rich- 2005

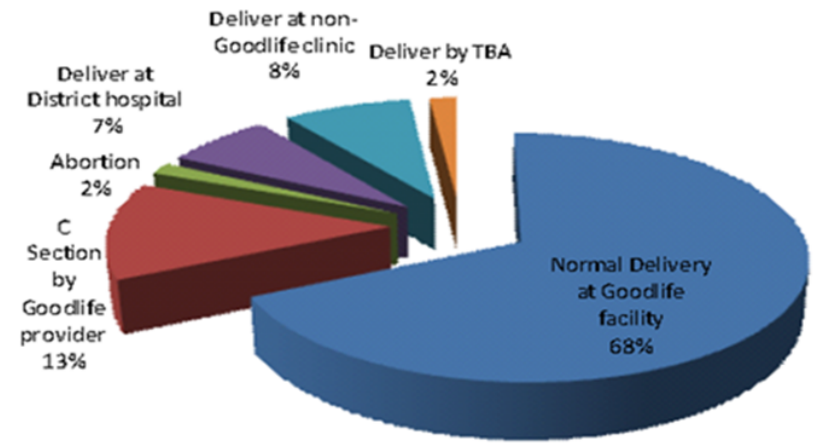

Graph 3: Result of recipients in DG Khan Pilot project of delivery at institution level 
Citation:Zafar M (2014) Impact of 'Pay for Performance' on Utilization of Health Services and Quality of Care in Low and Middle Income Countries. Health Care Current Reviews 2: 116. doi: 10.4172/2375-4273.1000116

Page 4 of 8

\begin{tabular}{|l|l|l|}
\hline Indicators & Poorest Countries & Richest countries \\
\hline Life expectancy at birth (years) & 58 & 78 \\
\hline Infant mortality rate (per 1,000 live births) & 80 & 5 \\
\hline Under-5 mortality rate (per 1,000) & 123 & 7 \\
\hline Maternal mortality ratio (per 100000 live birth) & 689 & 13 \\
\hline
\end{tabular}

Table 1: The data show that child-birth for women in poorest countries is extremely dangerous as 689 poor women die in child birth per 100,000 live births in contrast to 13 in the richest quintile. Life expectancy at birth is 20 years lower for the poorest countries than for the richest worldwide

\begin{tabular}{|c|c|c|}
\hline Level & Constraint or Underlying Performance Problem & P4P Solutions \\
\hline \multirow{4}{*}{$\begin{array}{l}\text { Household/ } \\
\text { Community Level }\end{array}$} & $\begin{array}{l}\text { 1. Households can't afford to obtain quality care: Financial } \\
\text { barriers }\end{array}$ & $\begin{array}{l}\text { Conditional cash transfer(CCT) Programs: Directly } \\
\text { increase household income and reduce prices of essential } \\
\text { services. Also inhibits household decisions to purchase low } \\
\text { cost substitutes. } \\
\text { Transportation subsidies: reduce direct cost of obtaining } \\
\text { care. } \\
\text { Food support: Frees up income that would have been used } \\
\text { to buy food. Reduces opportunity costs of seeking care- espe- } \\
\text { cially for treatment of chronic condition. }\end{array}$ \\
\hline & \multirow{3}{*}{$\begin{array}{l}\text { 2. Health care services are hard to reach: Physical barriers } \\
\text { to access }\end{array}$} & $\begin{array}{l}\text { Transportation subsidies: reduce direct cost of obtaining } \\
\text { care. }\end{array}$ \\
\hline & & $\begin{array}{l}\text { Financial rewards: to providers for results (and/or penal- } \\
\text { ties for poor performance): Financial incentives to providers } \\
\text { stimulate outreach, offer more convenient clinic hours, and } \\
\text { reduce financial barriers faced by households. }\end{array}$ \\
\hline & & $\begin{array}{l}\text { Provide per diems and vehicles to enable providers to } \\
\text { reach remote areas: Can be an incentive if per diems exceed } \\
\text { incurred travel costs and vehicles are also used for personal } \\
\text { use. }\end{array}$ \\
\hline \multirow{3}{*}{ Service Provision Level } & $\begin{array}{l}\text { 1. Inadequate supply, maldistribution, and poor motivation } \\
\text { of health workers: Staffing challenges. }\end{array}$ & $\begin{array}{l}\text { Financial rewards to providers for results (and/or } \\
\text { penalties for poor performance): Financial incentives that } \\
\text { reward results can motivate solutions to the model of service } \\
\text { delivery that may include strategies to improve outreach to } \\
\text { underserved areas, utilization of changed mix of health care } \\
\text { workers, and payments conditional on achieving results (or } \\
\text { penalties for not) can motivate effort and innovative solutions. }\end{array}$ \\
\hline & $\begin{array}{l}\text { 2. Weak technical guidance, program management, and } \\
\text { supervision: Management challenges }\end{array}$ & $\begin{array}{l}\text { Financial rewards to health service providing institutions } \\
\text { for results (and/or penalties for poor performance): Finan- } \\
\text { cial incentives that reward results can strengthen manage- } \\
\text { ment by causing service providing institutions to examine the } \\
\text { range of constraints they face to achieving results and the } \\
\text { systems, capabilities, and strategies they need to introduce to } \\
\text { achieve them. }\end{array}$ \\
\hline & 3. Drugs and supplies not available: Drugs and supplies & $\begin{array}{l}\text { Contract out drug procurement, storage, and distribu- } \\
\text { tion: Reward contracted entities based on results (example: } \\
\text { reduced drug stock outs). } \\
\text { Performance based incentives in inventory management } \\
\text { and distribution: Increase responsiveness by improving } \\
\text { management systems from central to regional levels and to } \\
\text { facility levels. }\end{array}$ \\
\hline \multirow{4}{*}{ Health Sector Level } & $\begin{array}{l}\text { 1. Inequitable and inefficient distribution of resources for } \\
\text { health: Resource allocation }\end{array}$ & $\begin{array}{l}\text { National to local transfers based on results: Payment to } \\
\text { providers to provide services to the poor. Can be part of a } \\
\text { social insurance scheme, a contracting process for the private } \\
\text { sector, a system to reward public sector providers or combina- } \\
\text { tions }\end{array}$ \\
\hline & $\begin{array}{l}\text { 2. Weak and overly centralized systems for planning and } \\
\text { management: Planning and Management }\end{array}$ & $\begin{array}{l}\text { National to local transfers based on results: stimulate de- } \\
\text { velopment of stronger local level management and planning. }\end{array}$ \\
\hline & 3. Poor quality of care: Quality Assurance. & $\begin{array}{l}\text { Financial rewards to providers for results (and/or penal- } \\
\text { ties for poor performance): Financial incentives to providers } \\
\text { for results to stimulate improvements in technical quality and } \\
\text { responsiveness. Provide incentives so it is in providers' inter- } \\
\text { est to adhere to quality standard. }\end{array}$ \\
\hline & $\begin{array}{l}\text { 4. Weak incentives for providers to be efficient and respon- } \\
\text { sive: Incentives }\end{array}$ & $\begin{array}{l}\text { Financial rewards to providers for results (and/or penal- } \\
\text { ties for poor performance): Financial incentives that reward } \\
\text { results can improve both efficiency and responsiveness. } \\
\text { Social insurance that provides universal coverage and } \\
\text { pays providers based on performance: Can be part of a } \\
\text { 'Pay for performance' intervention if payment is based on } \\
\text { results that stimulate efficiency and responsiveness. }\end{array}$ \\
\hline
\end{tabular}

Table 2: Distinguish Features of 'Pay for Performance 


\begin{tabular}{|l|l|l|l|}
\hline Indicator & Control & Contracted-In & Contracted-Out \\
\hline Antenatal Care & 160 & 233 & 0 \\
\hline Trained Delivery & 26 & 225 & 402 \\
\hline Facility Delivery & 0 & 149 & 0 \\
\hline Antenatal Tetanus Immunization & 149 & 301 & 142 \\
\hline Family Planning Knowledge & 307 & 105 & 400 \\
\hline Contraceptive prevalence Rate & 93 & 82 & 560 \\
\hline Child Immunization & 56 & 30 & 123 \\
\hline Vitamin A capsule Recipient & -25 & 491 & 158 \\
\hline $\begin{array}{l}\text { Percent of illness treated in public health facility- } \\
\text { lower 50\% socioeconomic status }\end{array}$ & 82 & 24 \\
\hline
\end{tabular}

Table 3: Average Percentage Change in Health Service Coverage Indicators in Cambodia

\section{CASE 1: Pakistan [15]}

Population covered: 2.2 million living in Dera Ghazi khan districts.

Description of performance problem(s): Pregnant women visits clinic for antenatal checkup are significantly lower in rural areas, only 20 percent of women make four or more antenatal checkup in rural areas as compared with 62 percent of women in major urban areas. In Pakistan demographic health survey (PDHS) 2006-2007 found that main barriers to antenatal checkup in clinic are were lack of awareness about the benefits of care ( 70 percent of women), high cost of access to healthcare facilities (20 percent) and transport/distance concerns (10 percent cases).

Brief description of the model: In October 2008, Greenstar which is non-government organization selected Dera Ghazi (DG) Khan district in Punjab province, a low-income district with the highest unmet need of family planning. Incentive given to pregnant women is voucher which give benefit to the pregnant women to free of cost antenatal checkup in clinic. They recruited 2,000 pregnant women living in DG Khan to utilize the voucher scheme within a 12-month period. Greenstar had to convince clients to access the services, which meant doing outreach working with home-based decision makers.

Result: Result shows that delivery of baby in facility increased to $98 \%$ compared to $20 \%$ before intervention, $68 \%$ in Greenstar provide facility (Graph 3).

\section{CASE 2: Cambodia}

Population covered: 1 million living in 9 districts in 3 provinces.

Services provided: maternal and child health services

Description of performance problem(s) the program is trying to solve: In the 1993 post-conflict period, Cambodia had limited health human resources, little rural health infrastructure, and poor quality of care. This program was intended to increase access and utilization by expanding availability of services to underserved populations with the ultimate result of improving maternal and child health outcomes.

Results: Result shows that performance of healthcare facilities improved after intervention. Table 3 shows that every indicator improved as compared to control.

CASE 3: Nicaragua conditional cash transfer program

Population covered: 6,000 households in 21 census comarcas in six municipalities in the northern part of the central region of Nicaragua.

Services supported: Basic health and nutrition services and education
Description of performance problem(s) the program is trying to solve:

Phase 1 (2000-2002)

1) Improve household overall diet by increase overall expenditures on food through income transfers.

2) Improve nutritional status of children under 5.

3) Increase enrollment, reduce desertion and enhance school progression during the first 4 years of primary school.

Phase 2 (2002-2005)

1) Additional improvements in all of phase 1 target.

2) Improve maternal health including family planning

Demand side incentives: Eligible households, determined by a combination of geographical and household level targeting, are provided a cash transfer equal to US\$224 per year, paid every 2 months. Receipt of this payment in Phase 1 was conditional on attending health education workshops and taking children under 5 for mandated health care appointments (monthly visits for children under 2, bimonthly for ages 2-5). In Phase 2, this payment was significantly reduced while the required service package was expanded to include maternal health and family planning services.

Supply side incentives: Supply of health services is by contracted private providers, chosen through a competitive process, private provider are trained and paid a per capita payment of US\$130 per year per household to deliver the services covered by the program free of charge. In Phase 1, services included: growth monitoring and development monitoring, vaccinations, provision of anti-parasites, vitamins and iron supplements for children. In Phase 2, maternal health and family planning services were added. Providers receive $3 \%$ of the annual maximum payment in advance. The other $97 \%$ is conditional on achieving performance targets.

Financing: There is a Red de Protection Social (RPS) project management unit housed in the Ministry of Family (MIFAMILIA). This unit contracts private agencies to manage payment to households. This unit also pays private health care providers directly.

Performance measured: A census of socio-demographic characteristics of households residing in RPS municipalities is carried out by MIFAMILIA to establish baseline data and to determine household eligibility to receive subsidies. When households visit health providers they have to sign (finger print) a form testifying that they have received a specific service. Providers have to hand MIFAMILIA these lists in order to receive payments for the services delivered. All this information is downloaded in the management information system 
(MIS) managed by MIFAMILIA. Each household keeps a form that records health care services received by all members of the household. MIFAMILIA carry out random controls to verify that services are being delivered as reported by providers. In addition, every two months the IADB (audit agency) carries out random audits of a sample of providers and households selected from the roster contained in the MIS to verify that reported services were actually delivered to households. During these checks both providers and households are interviewed and records analyzed.

Case 4: Janani suraksha yojna by indian ministry of health and family welfare

Implementation of JSY in 2007-08 was highly variable by statefrom less than $5 \%$ to $44 \%$ of women giving birth receiving cash payments from JSY. The poorest and least educated women did not always have the highest odds of receiving JSY payments. JSY had a significant effect on increasing antenatal care and in-facility births. In the matching analysis, JSY payment was associated with a reduction of 3.7 (95\% CI 2.2-5.2) perinatal deaths per 1000 pregnancies and $2.3(0.9-3.7)$ neonatal deaths per 1000 live births. In the with-versuswithout comparison, the reductions were $4 \cdot 1(2 \cdot 5-5 \cdot 7)$ perinatal deaths per 1000 pregnancies and $2 \bullet 4(0 \bullet 7-4 \bullet 1)$ neonatal deaths per 1000 live births.

Case 5: An experiment in payment reform for doctors in rural China reduced some unnecessary care but did not lower total costs

Inefficiency and low quality of health services are common in many developing countries. To mitigate these problems, we conducted an experiment in rural China in which we changed the existing feefor-service method of paying village doctors to a mixed payment method that included a salary plus a bonus based on performance. The new payment method also removed a feature that previously allowed doctors to purchase medications to prescribe to patients and earn a markup on each prescription. Changing these payment incentives reduced spending at the village level, curbed unnecessary care for healthier patients, and also decreased the prescribing of unnecessary drugs. However, other features of the arrangement encouraged doctors to refer sicker patients to township and county facilities, where costs were higher. As a result, total health care spending was not significantly reduced. The findings underscore that policy makers should design payment methods carefully to both contain costs and improve quality.

Case 6: Value for money and the quality and outcomes framework in primary care in the UK

The Quality and Outcomes Framework (QOF) is a pioneering attempt to improve the quality of primary care in the UK through the use of financial rewards. Despite its achievements, there are concerns that the QOF may offer poor value for money.

Aim: To assess the cost-effectiveness of QOF payments.

Methods: Cost-effectiveness evidence was identified for a subset of nine QOF indicators with a direct therapeutic impact. These data were then applied to an analytic framework to determine the conditions under which QOF payments would be cost-effective. This framework was constructed to assess the cost-effectiveness of QOF payments by modeling the incentive structure using cost-effectiveness thresholds of 20000 and 30000 UK pounds per quality-adjusted life year (QALY) gained, to represent good value to the NHS. It used 2004/2005 data on the QOF performance of all English primary care practices.

Result: Average indicator payments ranged from 0.63 to 40.61
UK pounds per patient, and the percentage of eligible patients treated ranged from $63 \%$ to $90 \%$. The proportional changes required for QOF payments to be cost-effective varied widely between the indicators. Although most indicators required only a fraction of a $1 \%$ change to be cost-effective, for some indicators improvements in performance of around $20 \%$ were needed.

\section{Discussion}

Pay for performance in health care is based on set of assumption of uncertain validity. Financial incentive will motivate behavioral change such as improve in quality and performance in health outcome [17]. Pay for performance based scheme should be viewed as dynamic system that need to be tailored and need to different professional groups, service and patient. Initial studies suggest that pay-for-performance programs can change performance on quality measures that are used for the basis of bonus payments, but contentions that pay-for performance programs are cost-saving in the long run are largely unsubstantiated [18].

Regarding effectiveness, most studies have focused on prevention and chronic care provision in primary care. Results of the few studies with strong designs are mixed, justifying the conclusion that there is insufficient evidence to support or not support the use of P4P [19]. Non-randomized studies have typically found improvements in at least one measure, although results from studies with relatively strong designs (level II) were generally less positive than results from studies with weaker designs (levels III and IV) [20,21]. Overall, the impact of physician $\mathrm{P} 4 \mathrm{P}$ has been estimated at $5 \%$ improvement in incentivized performance measures. The reviews further highlight P4P's potential to be cost-effective. Yet most studies use narrow cost and effect ranges [22]. In addition, the evidence largely pertains to relatively small programs. Two recent articles not included in the reviews (level III and II) provide additional evidence that P4P can potentially be cost-effective. Walker et al. found that QOF payments were potentially a cost-effective use of resources for most GPs for most of the nine evaluated measures, but QOF administration costs, which are substantial, were not taken into account [23].

Regarding unintended consequences, the reviews identified one study finding evidence of risk selection [24]. Several other studies provide additional evidence. A qualitative study from California found that the inability to exception report led some physicians to deter noncompliant patients [25]. In addition, Wang et al. (level II) found that physicians referred more severely ill patients to higher-cost facilities under a performance-based incentive system in rural China [26]. Level III showed that older patients and patients with greater disease severity/ comorbidity were more likely to not be included in the diabetes P4Pprogram in Taiwan than younger and healthier patients (level II) had a similar finding [27]. There is some evidence of (negative) spillover effects, with some studies finding reductions in continuity of care and less improvement for excluded conditions than for included conditions. Two recent studies (level II and III) back this finding: Campbell et al. found a reduction in continuity of care after QOF implementation $[28,29]$. It was found that although incentivized and un-incentivized aspects improved, improvements associated with financial incentives seem to have been achieved at the expense of small detrimental effects on un-incentivized measures [30]. Evidence on gaming behavior and negative effects on providers' intrinsic motivation is virtually absent, although a recent study (level III) revealed that GPs in the UK probably gamed the system of exception reporting to some extent [31].

There are some limitations associated with our review. First, although evidence is available on a wide variety of effects, most 
domains are only partially covered due to a limited number of studies with strong designs (e.g., cost-effectiveness) or a concentration of studies on a single program (e.g., effectiveness of hospital $\mathrm{P} 4 \mathrm{P}$ and the impact on inequalities). Second, the included reviews lack important information on the context in which studies were conducted, such as the base payment system (e.g., P4P payments may be smaller under capitation than under FFS because of lower opportunity costs of improving performance), essential infrastructure (e.g., data collection systems), and health system features. Third, research on the effects of $\mathrm{P} 4 \mathrm{P}$ continues to be concentrated in the US and the UK. Although an increasing number of studies from other countries have been published in the last 5-10 years, it is difficult to generalize our findings to other high-income countries or any low- or middle-income country. Finally, we did not systematically verify the information reported in the reviews by consulting individual studies, which may have introduced bias (e.g., resulting from inaccurate reporting of findings from individual studies within reviews).We encountered virtually no conflicting reports and interpretations, so the reviews' representation of the evidence is likely to be sufficiently adequate and the bias arising from our approach limited.

\section{Implications for Research and Policy}

First, although many studies have found improvements in selected quality measures and suggested that $\mathrm{P} 4 \mathrm{P}$ can potentially be effective, at this point the evidence seems insufficient to recommend widespread implementation of P4P.Second, thus far P4P evaluations have mainly focused on testing the short-term impact on clinical processes (e.g., screening for cancer, periodically performing eye exams for diabetes patients) and, to a lesser extent, intermediate outcomes (e.g., HbAlc levels of diabetes patients). However, the ultimate goal of $\mathrm{P} 4 \mathrm{P}$ will typically be to improve patient health outcomes in the long run. Third, although evidence is limited, P4P may have several unintended effects, underscoring the importance of ongoing monitoring and more insight in how specific design features may help in mitigating incentives for undesired behavior. Fourth, although it is reassuring that P4P does not seem to have widened inequalities, most studies relied on crosssectional data from the UK and many inequalities have persisted. Finally, an important lesson is that improving performance via $\mathrm{P} 4 \mathrm{P}$ is not straightforward. Important preconditions need to be fulfilled, including active provider engagement and support, adequate risk adjustment, a transparent information system for collecting performance data and for monitoring for undesired behavior, and a design that is tailored to the specific setting of implementation.

\section{Conclusion}

We have sufficient evidence to understand what works, under what situation estimated and inadvertent consequences. Emerging evidence suggests that pay for performance may help shape high performance delivery systems; there are also big pitfalls which must be addressed to maximize its benefit. Challenges that remain are not merely the technical aspects of design but go to the heart of the ideological debate over performance motivation.

\section{Conflict of Interests}

The authors declare that they have no competing interests.

\section{Acknowledgments}

We would like to thank Dr Nelofar Sami, Peter hatcher at Aga Khan University reviewers for their helpful comments on earlier drafts of this paper.

\section{References}

1. Nishtar S (2006) The Gateway paper- towards a health systems reform.

2. Eichler R (2006) Can pay for performance increase utilization by the poor and improve the quality of health services. Background papers for the Working Group on Performance Based Incentives Centre for Global Development.

3. Khattak FH (2004) Budget and national health accounts of health sector in Pakistan. Planning Commission, Government of Paksitan.

4. Government of Pakistan (2004) Statistical Year Book 2004. Ministry of Finance Islamabad, Pakistan.

5. Dodd R, Himshelwood E (2002) Poverty Reduction Strategy Papers - their significance for health. World Health Organization, Geneva, Switzerland.

6. World Health Organization (2012) National expenditure on heath - Pakistan

7. Government of Pakistan (2002) Pakistan Integrated Household Survey. Federal Bureau of Statistics, Islamabad, Pakistan.

8. Gwatkin DR, Guillot M, Heuveline P (1999) The Burden of Disease among the Global Poor. Lancet 354: 586-589.

9. Castro-Leal F, Dayton J, Demrey L, Mehra K (2000) Public Spending on Health Care in Africa: Do the Poor benefit? Bull World Health Organ 78: 66-74.

10. Makinen M, Waters $H$, Rauch M, Almagametova N, Bitran R, et al. (2000) Inequalities in Health Care Use and Expenditures: Empirical Data from Eight Developing Countries and Countries in Transition. Bull World Health Organ 78: $55-65$

11. Ensor T, Cooper S (2004) Overcoming Barriers to Health Services: Influencing the Demand Side. Health Policy Plan 19: 69-79.

12. Gwatkin DR (2002) Reducing Health Inequities in Developing Countries (4thedn), Oxford Textbook of Public Health.

13. Rusen ID (2005) Monitoring and Evaluation of FIDELIS Projects, presented at the Union meeting in Paris, France.

14. Evans T (2005) Montreux Challenge: Making Health Systems Work, World Health Organization

15. Bashir H, Kazmi S, Eichler R, Beith A, Brown E (2009) Pay for Performance: Improving Maternal Health Services in Pakistan. Health systems 20/20 project Abt associates Inc.

16. Gold M (1999) The changing US health care system: challenges for responsible public policy. Milbank Q 77: 3-37.

17. Arrow K (1963) Uncertainty and the welfare economics of medical care. Am Econ Rev 53: 941-973.

18. Blomqvist $A$ (1991) The doctor as double agent: information asymmetry, health insurance, and medical care. J Health Econ 10: 411-432.

19. Dranove D, White WD (1987) Agency and the organization of health care delivery. Inquiry 24: 405-415.

20. Scott A (2001) Eliciting GPs' preferences for pecuniary and non-pecuniary job characteristics. J Health Econ 20: 329-347.

21. Eisenberg JM (1985) Physician utilization. The state of research about physicians' practice patterns. Med Care 23: 461-483.

22. Wennberg JE, Barnes BA, Zubkoff M (1982) Professional uncertainty and the problem of supplier-induced demand. Soc Sci Med 16: 811-824.

23. Walker S, Mason A, Claxton K, Cookson R, Fenwick E, et al. (2010) Value for money and the quality and outcomes framework in primary care in the UK NHS. Br J Gen Pract 60: e213-e220.

24. Adato M, Maluccio J (2005) Evaluation of Phases I and II of the Red de Protección Social-Mi Familia in Nicaragua, IADB.

25. McDonald R, Roland M (2009) Pay for performance in primary care in England and California: comparison of unintended consequences. Ann Fam Med 7 : 121-127.

26. Wang H, Zhang L, Yip W, Hsiao W (2011) An experiment in payment reform for doctors in rural China reduced some unnecessary care but did not lower total costs. Health Aff 30: 2427-2436.

27. Chen T, Chung K, Lin I, Lai M (2011) The unintended consequence of diabetes mellitus pay-for-performance ( $\mathrm{P} 4 \mathrm{P})$ program in Taiwan: are patients with more comorbidities or more severe conditions likely to be excluded from the P4P program? Health Serv Res 46: 47-60. 
Citation:Zafar M (2014) Impact of 'Pay for Performance' on Utilization of Health Services and Quality of Care in Low and Middle Income Countries. Health Care Current Reviews 2: 116. doi: 10.4172/2375-4273.1000116

Page 8 of 8

28. Chang R, Lin S, Aron DC (2012) A pay-for-performance program in Taiwan improved care for some diabetes patients, but doctors may have excluded sicker ones. Health Aff 31: 93-102.

29. Campbell SM, Kontopantelis E, Reeves D, Valderas JM, Gaehl E, et al. (2007) Changes in patient experiences of primary care during health service reforms in England between 2003 and 2007. Ann Fam Med 8: 499-506.
30. Doran T, Kontopantelis E, Valderas JM, Campbell S, Roland M, et al. (2011) Effect of financial incentives on incentivised and non-incentivised clinical activities: longitudinal analysis of data from the UK Quality and Outcomes Framework. BMJ 342: d3590.

31. Gravelle H, Sutton M, Ma A (2010) Doctor Behavior under a pay for performance contract: treating, cheating and case finding? The Economic Journal: The Journal of the Royal Economic Society 120: F129-F156. 